УДК 615.015:616.831.-006.6576.3/4

\title{
Лисянъй Н.И.
}

Отдел нейроиммунологии, Институт нейрохирургии им. акад. А.П. Ромоданова НАМН Украины, г. Киев, Украина

\section{Метформин - новое средство для профилактики и лечения злокачественных опухолей человека}

Метформин широко применяют в качестве антидиабетического препарата, в последние годы обнаружены его противоопухолевые свойства. По данным эпидемиологических исследований показано уменьшение частоты появления рака у больных сахарным диабетом, которым назначали метформин.

Метформин снижает инсулинорезистентность и предупреждает возникновение рака поджелудочной железы. Доказано прямое тормозящее действие метформина на рост раковых клеток. Кроме того, метформин активирует АМФ-зависимую протеинкиназу (АМФПК), которая влияет на энергетическое состояние клеток и этим достигается противоопухолевый эффект.

Ключевые слова: сахарный диабет, метфорлин, злокачественные опухоли человека, опухоли головного мозга.

Сорок лет тому назад установлено, что антидиабетические препараты группы бигуанидов (метформин, оренформин, буфонин), полученные из травы Galega officinales (французская лиана, козья рута), помимо антидиабетического, оказывают геропротекторное и противоопухолевое действие, увеличивая на 10-30\% продолжительность жизни животных [1-4], а также тормозят развитие спонтанных или индуцированных опухолей у животных в зависимости от примененных доз препаратов и длительности курса лечения [5-8]. Так, при длительном применении метформина у самок мышей линии $\mathrm{C} 3 \mathrm{H} / \mathrm{SH}$ в 4 раза реже возникали спонтанные аденокарциномы [6], в 1,6 раза - спонтанные опухоли у крыс [7, 8]. При ежедневном применении метформина реже возникали опухоли после введения канцерогенов у мышей и крыс, в том числе опухоли грудной железы у крыс после введения бензантрацена или нитрозометил мочевины [9-11]. Метформин ингибировал рост аденокарциномы кишечника у крыс после введения диметилгидрозина, нормализовал уровень глюкозы, инсулина, триглицеридов, повышал иммунный статус, угнетение которого наблюдали при действии канцерогена $[11,12]$. Результаты экспериментальных исследований у животных нашли подтверждение у человека. Так, у больных сахарным диабетом II типа, которым назначали метформин, достоверно меньшей была частота возникновения онкологических заболеваний, чем у больных, применявших инсулин и другие противодиабетические препараты $[13,14]$. Хотя есть и другие данные, в частности, метформин не влиял на частоту возникновения рака предстательной железы у больных диабетом [15].

Механизм действия метформина на опухолевые клетки до конца не изучен, выделяют два возможных механизма: прямой инсулинзависимый и непрямой инсулинзависимый путь [16-18]. Прямое влияние предполагает, что метформин, проникая в клетку, активирует АМФПК, которая, в свою очередь, блокирует активность рапамицинзависимого сигнального пути (mTOR), ответственного за пролиферацию клеток многих видов опухолей [16, 17]. Непрямой механизм действия метформина обусловлен снижением в крови уровня инсулина, который является важным компонентом пролиферации опухолевых клеток, поскольку они содержат на своей поверхности инсулинсвязывающий фрактор. Инсулин, связываясь с этим рецептором, запускает активацию и пролиферацию опухолевых клеток [18-20].

Особый интерес к метформину как противоопухолевому препарату возник после 2000 г. Во всем мире ведутся широкие исследования по изучению механизмов противоопухолевого действия препарата, а также возможности его широкого клинического применения. Только за последние 3 года опубликованы более 30 обзоров, посвященных метформину [21-23].

Установлено прямое влияние метформина на рост опухолевых клеток в опытах in vitro. Так, метформин подавлял пролиферацию различных клеточных линий опухолей, включая опухоль легкого, предстательной железы, аденомы грудной железы, яичка, кишечника при внесении его в культуру клеток в дозе от 5 до 30 ммоль на 1 мл среды. Установлено, что в различных видах опухоли клетки по-разному чувствительны к метформину. Так, линия LNCAP клеток предстательной железы более чувствительна, чем линия HCF-7 рака грудной железы. Даже в пределах одного вида опухоли различные линии клеток имеют разную индивидуальную чувствительность к препарату [17]. В то же время, многие авторы обращают внимание на дозы метформина, используемые в экспериментах, наиболее часто 5-30 ммоль в 1 мл, что в 100-300 раз больше, чем рекомендованные для клинического применения при лечении сахарного диабета [23].

Малые дозы метформина также использовали в культуре клеток, установлено, что в дозе 0,1-0,3 ммоль/мл он угнетает только стволовые опухолевые клетки, резистентные к химиотерапевтическим препаратам [24]. Однако оказалось, что эти малые дозы не действуют на нестволовые интактные клетки. На клеточном уровне метформин угнетает клеточный цикл $\mathrm{G} 0 / \mathrm{G}$ и $\mathrm{S}$-фразу [23, 25]. Показано, что метформин останавливает клеточный цикл деления в фазе G0/G1 и уменьшает синтез циклина Д-1 в клетках опухоли предстательной железы in vitro, a также in vivo при трансплантации этих клеток животным [17]. Аналогичные результаты отмечены и в отношении клеток опухолей грудной железы, в 
которых под влиянием метформина останавливался клеточный цикл деления, повышался уровень p27 и р21, снижалось содержание циклина Д-1 [26]. Прекращение пролиферации в $\mathrm{S}$ фазе наблюдали в клетках опухолей поджелудочной железы и трижды негативных клеточных линиях рака грудной железы, что обусловливало апоптоз клеток [18]. В многочисленных исследованиях показано, что метформин также индуцирует апоптоз в различных опухолях [23, 27]. Помимо влияния на клеточный цикл, метформин способен угнетать некоторые рецепторы, снижать уровень онкорецептора Her2 (егвВ-2) - рецептора эпидермального фрактора роста в клеточных линиях опухолей поджелудочной железы и рака грудной железы [27, 28]. Это стало основанием или даже показанием к клиническому применению метформина при опухолях грудной железы в условиях гиперэкспресии этого рецептора в них, которую наблюдали в 10-30\% всех опухолей [23]. Показана возможность подавления экспрессии инсулинового рецептора на клетках опухоли поджелудочной железы. Полагают, что метформин включается во взаимодействие между инсулиновым и G-пептидсвязывающим рецепторами [29].

Антинеопластическое действие метформина доказано для некоторых опухолей на экспериментальных моделях. Так, впервые показано, что метформин предупреждает канцероген-индуцированную опухоль поджелудочной железы у хомяков, которых содержали на высококалорийной диете [30]. Установлено подавление роста клеточных линий PANC-1 и $\mathrm{HIAPa} \mathrm{Ca2}$ опухолей поджелудочной железы у трансгенных животных при ежедневном внутрибрюшинном введении метформина [29, 30].

Аналогичные результаты получены и с опухолью грудной железы, которую перевивали трансгенным мышам и вводили с метформином в дозе 100 мг/кг с питьевой водой. Установлено увеличение продолжительности жизни животных по сравнению с таковой в контрольной группе [31]. При введении метформина животным замедлялся рост различных опухолей в эксперименте, в том числе предстательной железы, легкого, толстого кишечника [17, 32, 33].

В то же время, есть и противоположное заключение о влиянии метформина на рост некоторых опухолей у экспериментальных животных [34]. Так, если in vitro метформин ингибировал рост клеток опухоли рака грудной железы, то in vivo - стимулировал экспрессию эндотелиальных фрракций роста сосудов, увеличивал прочность микрососудов в опухолях, размеры опухолевого очага [34]. В этих исследованиях использовали клеточную линию MDA-MB-435, которую одни исследователи относят к опухолевой линии рака грудной железы [34], другие - к линии меланомных клеток [35]. Подобные противоречия в результатах обусловлены как природой опухолевых клеток, так и дозой метформина. Так, в этих экспериментах использовали большие дозы - около 750 мг/кг в сутки, что в 45 раз больше доз, рекомендованных для клиники, и эти дозы ниже, чем использованные у мышей [17]. Это создает трудности в экстраполяции результатов от животных человеку, при попытке применения этого препарата для лечения опухолей человека.
Спорным является также вопрос о метаболических параметрах, в том числе уровне инсулинемии и гипогликемии при введении метформина. Так, одни авторы уделяют значительное внимание инсулинемии при лечении с применением метформина опухолей в эксперименте [36], другие - не учитывают его роль в реализации противоопухолевого эффекта и указывают на инсулиннезависимый механизм действия препарата [24, 31, 36]. Нерешенной проблемой применения метформина в клинике является также возможность возникновения гипогликемии у больных при нормогликемии и других побочных реакций. Окончательно вопрос не решен, однако проводятся достаточно широкие исследования по использованию метформина в клинике [36-38], в том числе в сочетании с химиотерапией, особенно при опухолях грудной железы [23].

Несмотря на отсутствие данных о влиянии метформина на опухоли головного мозга, представляются важными сведения о его влиянии на другие опухоли, поскольку механизмы онкогенеза во многом универсальны и существенно не зависят от типа ткани, из которой они возникают.

Проведены многочисленные исследования по изучению влияния метформина на опухоли грудной, предстательной желез, легкого, исследований о его влиянии на злокачественные опухоли мозга недостаточно. Так, в единственной работе изучена способность метформина останавливать клеточный цикл G/ G-1 в культуре клеток глиомы и индуцировать в них апоптоз [39]. В клиническом исследовании, выполненном румынскими авторами, показана возможность применения метформина на фоне химиотерапии с применением темодала (saniton). Установлено, что 7 из 8 исследованных глиобластом оказались малочувствительны in vitro к темодалу, при добавлении в культуру метформина - 6 из 8 [23].

Метформин особенно активно блокирует фрункции стволовых опухолевых клеток. Так, в культуре in vitro в малых дозах (1-10 ммоль) он подавлял образование клетками карциномы грудной железы нейросфрер, пролиферацию и экспрессию маркеров стволовых клеток, в частности, ОСТ-4, это позволило авторам утверждать, что стволовые опухолевые клетки особо чувствительны к метформину [40].

Метформин вызывал повышение радиочувствительности радиорезистентных карцином шеи и головы, особенно в условиях мутации гена р-53 [41]

Метформин не только останавливал пролиферацию опухолевых клеток, он способен активировать апоптоз и аутофагию опухолевых клеток, что показано на культуре клеток меланомы на экспериментальных моделях [42]. В эксперименте показано, что метформин тормозит рост клеток яичников, трансплантированных внутрибрюшинно мышам, а также подавляет их метастазирование в легкие и лимфатические узлы. Особенно эффективно (до 90\%) угнетается метастазирование при введении вместе с цисплатином, что является весомым аргументом для использования метформина при лечении рака яичников [43].

Во многих исследованиях in vitro и in vivo, в экспериментах на nude мышах и на других моделях показано, что метфрормин действует на многие метаболические процессы в клетках опухоли. Основной 
точкой приложения метформина является повышение активности АМФПК, которая играет ключевую роль в регуляции энергетического гомеостаза. Метформин подавляет один из сигнальных путей, ответственный за пролиферацию клеток, так называемый mammalian target of rapamicin complex-1 (mTORC-1), что обусловливает значительное торможение пролиферации клеток [17].

Кроме того, метформин активирует онкосупрессорный ген, продуцирующий серин-триониновую киназу, которая, в свою очередь, влияет на фосфорилирование и активацию АМФПК, а также повышает уровень циклина Д-1 и т.д. [17, 44].

Метформин способен замедлять возникновение рака легкого, вызванного табаком. Так, у мышей при введении табачного канцерогена, возникали опухоли легкого, при введении метформина животным замедлялось возникновение опухолей, уменьшались их размеры и метастазы $[45,46]$.

Обобщая приведенные данные, можно сделать заключение, что метформин представляет новый класс противоопухолевых средств, который не является классическим химиотерапевтическим или таргетным препаратом, а посредством воздействия на энергетический метаболизм и активность внутриклеточных процессов вызывает торможение пролиферации и запуск процессов апоптоза и аутофагии опухолевых клеток. Важной особенностью препарата является блокирующее влияние на опухолевые стволовые клетки, ответственные за инвазивный рост, миграцию, метастазирование и возникновение новых очагов опухолевого роста.

Как показано в исследованиях, самостоятельное применение метформина не всегда обеспечивает противоопухолевый эфрфект, при его применении вместе с химиопрепаратами (цисплатином, доксорубицином, темодалом) или лучевой терапией удается достичь положительного результата, особенно при условии химио- и радиорезистентности опухолей. Молекулярные механизмы такого сочетанного действия метформина и химиопрепаратов окончательно не изучены. Но важно то, что метформин снижает резистентность опухоли и повышает ее чувствительность к действию химиопрепаратов, что позволит снизить дозы химиопрепаратов и уменьшить частоту осложнений после такого лечения.

Еще одной областью применения метформина может быть использование его для предупреждения возникновения и прогрессирования роста опухолей, особенно в группах повышенного риска. Приведенные экспериментальные исследования показывают, что метформин тормозит возникновение канцерогениндуцированных опухолей, в том числе рака легких, у мышей при введении табачного канцерогена. Пока это только экспериментально обоснованное предположение о профилактическом противоопухолевом применении этого препарата, его клиническое использование в этом плане еще не определено. По-видимому, в ближайшие годы будут получены новые данные и определены рекомендации по его применению с онкопрофилактической целью.

Трансформация представлений о механизме действия метформина как препарата, обладающего не только гипогликемическим действием и широко применяемого в диабетологии, но и значительным противоопухолевым и геропротекторным эффектом, позволяет надеяться на его широкое применение в онкологии, в том числе нейроонкологии. Не исключено, что существуют и другие, пока неизвестные препараты, способные подобно метформину, влиять на метаболизм как целого организма, так и опухолевой клетки, и тем самым оказывать противоопухолевое действие.

\section{Список литературы}

1. Dilman V.M. Ageing, metabolic immunodepression and carcinogenesis / V.M. Dilman // Mech Ageing Dev. — 1978 - V.8. - P.153-173.

2. Dilman V.M. Age-associated elevation of hypothalamic threshold to feedback control and its role in development, aging and disease / V.M. Dilman // Lancet. — 1971. — V.1. - P.1211-1219.

3. Pollak M. Metfromin and other biguanides in oncology: advancing the research agenda / M. Pollak //Cancer Prev. Res. - 2010. - V.3. - P.1060-1065.

4. Metformin extends life span of HER-2/neu transgenic mice and in combination with melatonin inhibits growth of transplantable tumors in vivo / V.N. Anisimov, P.A. Egormin, T.S. Piskunova,[et al.] // Cell Cycle. - 2010. - V.9. - P.188-197.

5. Metformin and cancer. Doses, mechanisms and the dandelion and hermetic phenomena / B. Martin-Castillo, A. Vazquez-Martin, C. Oliveras-Ferraros, [et al.] // Cell Cycle. - 2010. - V.9 . - P.1057-1064.

6. Metformin and energy metabolism in breast cancer: from insulin physiology to tumour-initiating stem cells / A. Vazquez-Martin ,C. Oliveras-Ferraros, S. Cufí [et al.] // Curr. Mol. Med. - 2010. - V.10. - P.674-691.

7. Dilman V.M. Effect of treatment with phenformin, dyphenylhydantoin or L-DOPA on life span and tumor incidence in $\mathrm{C} 3 \mathrm{H} / \mathrm{Sn}$ mice / V.M. Dilman, V.N. Anisimov // Gerontology. - 1980. - V.26. - P.241-245.

8. Anisimov V.N. Effect of buformin and diphenylhydantoin on life span, estrus function and spontaneous tumor incidence in female rats / V.N. Anisimov // Vopr. Onkol. — 1980. - V.6. - P.42-48.

9. On effect of phenformin on induction of mammary gland tumors in rats / V.M. Dilman, L.M. Berstein, M.A. Zabezhinski, V.A. Alexandrov // Vopr. Onkol. - 1974 - V.20. - P.94-97.

10. Anisimov V.N. Inhibition of blastogenic effect of 7.12dimethylbenz(a)-anthracene in female rats by buformin, diphenylhydantoin, polypeptide pineal extract and L-DOPA / V.N. Anisimov, M.N. Ostroumova, V.M. Dilman // Bull. Exp. Biol. Med. — 1980. — V.89. - P.723-725.

11. Vinnitski V.B. Effect of phenformin, L-DOPA and para-chlorophenylalanine on the immunological reactivity and chemical carcinogenesis in BALB/c mice / V.B.Vinnitski, V.A. Iakimenko // Vopr. Onkol. — 1981 - V.27. - P.45-50.

12. Anisimov V.N. Effect of phenformin on the blastomogenic action of 1.2-dimethylhydrazine in rats / V.N.Anisimov, K.M. Pozharisski, V.M. Dilman // Vopr. Onkol. - 1980. - V.26, N8. - P.54-58.

13. Abnormal glucose tolerance and the risk of cancer death in the United States / S.H. Saydah, C.M. Loria, M.S Eberhardt, F.L. Brancati // Am. J. Epidemiol. - 2003 - V.157. - P.1092-1100.

14. Diabetes mellitus and breast cancer, a retrospective population-based cohort study / L.L. Lipscombe, P.J. Goodwin, B. Zinman[et al.] // Breast Cancer Res. Treat. - 2006. - V.98. - P.349-356.

15. Clinical outcomes after radical prostatectomy in diabetic patients treated with metformin / T. Patel, G. Hruby, K. Badani [et al.] // Urology. - 2010. - V.75. - P.1240-1244. 
16. The antidiabetic drug metformin exerts an antitumoral effect in vitro and in vivo through a decrease of cyclin D1 level / I. Ben Sahra, K. Laurent, A. Loubat, [et al.] // Oncogene. - 2008. - V.27. - P.3576-3586.

17. Metformin induces unique biological and molecular responses in triple negative breast cancer cells / B. Liu, Z. Fan, S.M. Edgerton [et al.] // Cell Cycle. — 2009. - V.8. - P.2031-2040.

18. Understanding the benefit of metformin use in cancer treatment BMC / J.O. Ryan, I. Dowling, J.P. Goodwin [et al.] // BMC Medicine. - 2011. - V.9. - P.33-43.

19. Belfiore A. IGF and insulin receptor signaling in breast cancer / A. Belfiore, F. Frasca // J. Mam. Gland Biol. Neoplasia. - 2008. - V.13. - P.381-406.

20. The role of insulin receptors and IGF-I receptors in cancer and other diseases / F. Frasca, G. Pandini, L. Sciacca [et al.] // Arch. Physiol. Biochem. - 2008. - V.114. — P.23-37.

21. Insulin receptor is an independent predictor of a favorable outcome in early stage breast cancer / A.M. Mulligan, F.P. O’Malley, M. Ennis [et al.] // Breast Cancer Res. Treat. - 2007. - V.106. - P.39-47.

22. Metformin plus temozolomide-based chemotherapy as adjuvant treatment for WHO grade III and IV malignant gliomas / O. Soritau, C. Tomuleasa, M. Aldea [et al.] // J. BUON. - 2011. - V.16, N2. - P.282-289.

23. Metformin in cancer therapy: a new perspective for an old antidiabetic drug? / I. Ben Sahra, Y. Le MarchandBrustel, J.F. Tanti, F. Bost // Mol. Cancer. Ther. - 2010. - V.9. - P.1092-1099.

24. Gotlieb W.H. In vitro metformin anti-neoplastic activity in epithelial ovarian cancer / W.H. Gotlieb, J. Saumet, M.C. Beauchamp // Gynec. Oncol. - 2008. - V.110. - P.246-250.

25. Metformin selectively targets cancer stem cells, and acts together with chemotherapy to block tumor growth and prolong remission / H.A. Hirsch, D. Iliopoulos, P.N. Tsichlis [et al.] // Cancer Res. - 2009. - V.69. - P.507-511.

26. Zhuang Y. Cell cycle arrest in metformin treated breast cancer cells involves activation of AMPK, downregulation of cyclin D1, and requires p27Kip1 or p21Cip1 / Y. Zhuang, W.K. Miskimins // J. Mol. Signal. — 2008. - V.3. - P.18.

27. Metformin induces apoptosis of pancreatic cancer cells / L.W. Wang, Z.S. Li, D.W. Zou [et al.] // J. World Gastroenterol. — 2008. - V.14. - P.7192-7298.

28. Vazquez-Martin A. The antidiabetic drug metformin suppresses HER2 (erbB-2) oncoprotein overexpression via inhibition of the mTOR effector p70S6K1 in human breast carcinoma cells / A. Vazquez-Martin, C. Oliveras-Ferraros, J.A. Menendez // Cell Cycle. — 2009. - V.8. - P.88-96.

29. Metformin disrupts crosstalk between $\mathrm{G}$ protein-coupled receptor and insulin receptor signaling systems and inhibits pancreatic cancer growth / K. Kisfalvi, G. Eibl, J. Sinnett-Smith [et al.] // Cancer Res. - 2009. — V.69. - P.6539-6545.

30. Schneider M.B. Prevention of pancreatic cancer induction in hamsters by metformin / M.B. Schneider, H. Matsuzaki, J. Haorah // Gastroenterology. — 2001. — V.120. — P.12631270 .

31. Anisimov V.N. Effect of metformin on life span and on the development of spontaneous mammary tumors in HER2/neu transgenic mice / V.N. Anisimov, L.M. Berstein, P.A. Egormin // Exp. Gerontol. — 2005. — V.40. - P.685-693.

32. Metformin attenuates the stimulatory effect of a highenergy diet on in vivo LLC1 carcinoma growth / C. Algire, M. Zakikhani, M.J. Blouin [et al.] // Endocr. Relat. Cancer. - 2008. - V.15. - P.833-839.

33. Buzzai M. Systemic treatment with the antidiabetic drug metformin selectively impairs p53-deficient tumor cell growth / M. Buzzai, R.G. Jones, R.K. Amaravadi // Cancer Res. - 2007. - V.67. - P.6745-6752.

34. Phoenix K.N. Therapeutic metformin/AMPK activation promotes the angiogenic phenotype in the ERalpha negative MDA-MB-435 breast cancer model K.N. Phoenix, F. Vumbaca, K.P. Claffey // Breast Cancer Res. Treat. - 2009. - V.113. - P.101-111.

35. MDA-MB-435 cells are derived from M14 melanoma cells-a loss for breast cancer, but a boon for melanoma research / J.M. Rae, C.J. Creighton, J.M. Meck [et al.] // Breast Cancer Res. Treat. - 2007. — V.104. - P.13-19.

36 . Is it time to test metformin in breast cancer clinical trials? / M. Cazzaniga, B. Bonanni, A. Guerrieri-Gonzaga [et al.] // Cancer Epidemiol. Biomarkers Prev. — 2009. - V.18. - P.701-705.

37. Goodwin P.J. Metformin in breast cancer: time for action / P.J. Goodwin, J.A. Ligibel, V.J. Stambolic // Clin. Oncol. - 2009. - V.27. - P.3271-3273.

38. Martin-Castillo B. Incorporating the antidiabetic drug metformin in HER2-positive breast cancer treated with neoadjuvant chemotherapy and trastuzumab: an ongoing clinicaltranslational research experience at the Catalan Institute of Oncology / B. Martin-Castillo, J. Dorca, A. Vazquez-Martin //Ann. Oncol. - 2010. - V.21. - P.187-189.

39. Dual antiglioma action of metformin: cell cycle arrest and mitochondria-dependent apoptosis / A. Isakovic, L. Harhaji, D. Stevanovic [et al.] // Cell Mol. Life Sci. — 2007. — V.64. - P.1290-1302.

40. Metformin represses self-renewal of the human breast carcinoma stem cells via inhibition of estrogen receptormediated OCT4 expression / J.W. Jung, S.B. Park, S.J. Lee [et al.] // PLoS One. - 2011. — V.6, N11. — P.28068.

41. TP53 disruptive mutations lead to head and neck cancer treatment failure through inhibition of radiation-induced senescence / H.D. Skinner, V.C. Sandulache, T.J. Ow [et al.] // Clin. Cancer Res. - 2012. - V.18, N1. - P.290-300.

42. Metformin inhibits melanoma development through autophagy and apoptosis mechanisms / T. Tomic, T. Botton, M. Cerezo [et al.] //Cell Death Dis. — 2011. — V.2, N9. - P.199.

43. Metformin suppresses ovarian cancer growth and metastasis with enhancement of cisplatin cytotoxicity in vivo / R. Rattan, R.P. Graham, J.L. Maguire [et al.] // Neoplasia. - 2011. — V.13, N5. - P.483-491.

44. Micic D. Metformin: its emerging role in oncology / D. Micic, G. Cvijovic, V. Trajkovic [et al.] // Hormones (Athens). - 2011. - V.10, N1. - P.5-15.

45. Memmott R.M. Metformin prevent tobacco carcinogeninduced lung tumorigenesis / R.M. Memmott, J.R. Mercado, C.R. Maier // Cancer Prev. Res. (Phila). — 2010. — V.3. - P.1066-1076.

46. Antonoff M.B. Teaching an old drug new tricks: Metformin as a targeted therapy for lung cancer / M.B. Antonoff, J. D'Cunha // Seminars Thorac. Cardiovasc. Surg. - 2010. - V.22, N3. - P.195-196.

Поступила в редакицю 20.03.12 Принята к публикациии 11.04 .12

Адрес для переписки: Лисянъй Николай Иванович 04050, Киев, ул. П. Майбородъ, 32 Институт нейрохирургии им. акад. А.П. Ромоданова НАМН Украинъ, отдел нейроиммунологии e-mail: nimun.neuro@gmail.com 


\section{Лісяний М.I.}

Відділ нейроімунології, Інститут нейрохірургії ім. акад. А.П. Ромоданова НАМН України, м. Київ, Україна

\section{Метформін - новий засіб для профілактики та лікування злоякісних пухлин людини}

Меторормін широко використовують як антидіабетичний препарат, в останні роки виявлені його протипухлинні властивості. За даними епідеміологічних досліджень показане зменшення частоти виникнення раку у хворих на цукровий діабет, яким призначали метфомін.

Метформін знижує інсулінорезистентність і попереджає виникнення раку підшлункової залози. Доведений прямий гальмівний вплив метформіну на ріст ракових клітин. Крім того, метформін активує AMФ залежну протеїнкіназу, яка впливає на енергетичний стан клітин, і цим досягається протипухлинний ефект.

Ключові слова: иукровий діабет, метбормін, злоякісні пухлини людини, пухлини головного мозку.

Надійшла до редакиї 20.03.12 Прийнята до публікаиї 11.04 .12

Адреса для листування: Лісяний Микола Іванович 04050, Київ, вул. П. Майбороди, 32 Інститут нейрохірургї ім. акад. А.П. Ромоданова НАМН України, відділ нейроімунологї e-mail: nimun.neuro@gmail.com

\section{Lysyany N.I.}

Neuroimmunology Department, Institute of Neurosurgery named after acad. A.P. Romodanov NAMS Ukraine, Kiev, Ukraine

\section{Metformine - a new drug for the prevention and treatment of human malignant tumors}

Metformin is widely used antidiabetic drug in the world, in last years it's antitumor features have been revealed. Epidemiological studies show decreasing of cancer incidence at patients, been treated by metformin

Metformin decreases insulin-resistance and prevents emergence of pancreas cancer. Metformin's inhibiting influence on cancer cells growth was proved. More over, metformin activates protein-kinase, influencing on cells energetic status that provides antitumor effect.

Key words: diabetes, metformin, human malignant tumors, brain tumors.

Received March 20, 2012 Accepted April 11, 2012

Address for correspondence: Nikolay Lisyany 04050, 32 Platon Mayboroda St, Kiev, Ukraine Institute of Neurosurgery named after acad. A.P. Romodanov NAMS Ukraine, Neuroimmunology Department e-mail: nimun.neuro@gmail.com 